\title{
Anticoagulant potential and total phenolic content of six species of the genus Ficus from Azad Kashmir, Pakistan
}

\author{
Sumaira Ambreen ${ }^{1}$, Muhammad Tariq ${ }^{1 \star}$, Muhammad S Masoud ${ }^{2}$, Imran Ali ${ }^{1}$, \\ Muhammad Qasim², Aamar Mushtaq ${ }^{1}$, Maqsood Ahmed ${ }^{1}$, Rehana Asghar ${ }^{1}$ \\ ${ }^{1}$ Department of Biotechnology, Mirpur University of Science and Technology Mirpur 10250, AJK Pakistan, ${ }^{2}$ Department of \\ Bioinformatics and Biotechnology, Government College University, Faisalabad, Pakistan
}

*For correspondence: Email: tariq.awan@must.edu.pk; Tel: +92 5827961999

\begin{abstract}
Purpose: To investigate the total phenolic and flavonoid contents of Ficus benghalensis, Ficus elasticaa, Ficus palmata, Ficus religiosa, Ficus semicordata and Ficus auriculata, and to determine their anticoagulant potential.

Methods: Crude methanol extracts were prepared from the plant leaves, and fractionated using liquidliquid partition with $n$-hexane, chloroform and ethyl acetate. The total flavonoid and total phenolic contents of the extracts and their fractions were determined. The anticoagulant potential of the six Ficus species were evaluated in healthy human plasma, using activated partial thromboplastin time (APTT) and prothrombin time (PT) methods.

Results: Phytochemical analysis showed the presence of considerable amounts of flavonoids ranging from $5.3 \pm 0.7$ to $11.8 \pm 0.3 \mathrm{mg}$ rutin equivalents $(R E) / \mathrm{g}$, and phenolic compounds ranging from $8.0 \pm$ 0.7 to $86.5 \pm 1.5 \mathrm{mg}$ gallic acid equivalents (GAE)/g in each fraction of the six species. Results from in vitro anticoagulant potential assays showed significant anticoagulant properties, with prothrombin time $(P T)$ ranging from $17.7 \pm 0.7$ to $26.7 \pm 2.2 \mathrm{~s}$, and activated partial thromboplastin time (APTT) varying from $47.7 \pm 3.3$ to $72.3 \pm 5.4 \mathrm{~s}$.

Conclusion: The results indicate that $F$. semicordata and F. Religiosa have higher anticoagulant potential than the other Ficus species studied.
\end{abstract}

Keywords: Medicinal plants, Anticoagulant, Polyphenols, Flavonoids, Ficus

This is an Open Access article that uses a fund-ing model which does not charge readers or their institutions for access and distributed under the terms of the Creative Commons Attribution License (http://creativecommons.org/licenses/by/4.0) and the Budapest Open Access Initiative (http://www.budapestopenaccessinitiative.org/read), which permit unrestricted use, distribution, and reproduction in any medium, provided the original work is properly credited.

Tropical Journal of Pharmaceutical Research is indexed by Science Citation Index (SciSearch), Scopus, International Pharmaceutical Abstract, Chemical Abstracts, Embase, Index Copernicus, EBSCO, African Index Medicus, JournalSeek, Journal Citation Reports/Science Edition, Directory of Open Access Journals (DOAJ), African Journal Online, Bioline International, Open-J-Gate and Pharmacy Abstracts

\section{INTRODUCTION}

Cardiovascular diseases (CVDs) are associated with poor health and high incidence of death worldwide [1]. The major cause of death in CVD patients is thrombus-induced myocardial infarction which also contributes to the pathogenesis of atherosclerotic CVDs [1].
Abnormal coagulation leads to the formation of thrombus in blood vessels resulting in ischemia [1]. In atherosclerotic arteries, platelet activation induces arterial thrombosis [2]. Therefore, it is important to regulate platelet function in order to prevent thrombotic events. However, the currently available antithrombotic and antiplatelet drugs produce unsatisfactory results, and often 
lead to vascular relapses. Indeed, most thromboembolic processes require anticoagulant therapy. Therefore, there is need for development of novel, more effective and less toxic bioactive anticoagulant and antithrombotic drugs with different mechanisms of action. Anticoagulants arrest coagulation after the initial platelet aggregation with blood clotting factors [3]. Generally, anticoagulation therapy reduces the severity of CVDs, and prevents existing clots from growing larger [4]. Anticoagulants reduce the formation of blood clots in other vital organs such as lungs and brain [3]. Moreover, they diminish the risks of developing other diseases such as atrial fibrillation, deep vein thrombosis, myocardial infarction, stroke and pulmonary embolism [3,4]. Although anticoagulants such as heparin, aspirin and warfarin are often used in clinical practice, some patients may develop aspirin resistance. Therefore, natural sources of anticoagulants (plants/herbs) may provide alternative and safer therapy for thrombotic disorders [3]. Herbal drugs have shown great efficacy in the treatment of many diseases. According to the World Health Organization (WHO), about $25 \%$ of drugs used in the world are plant-based [5]. Indeed, in many parts of the world, there is a significant preference for herbs over orthodox drugs for primary health care. The high cost of synthetic medicines and their limited supply to rural areas in many developing countries have driven the continuous dependence on traditional herbal medicines [6]. Medicinal plant-based products are used as raw material in several multibillion-dollar industries all over the world [7].

The genus Ficus of the Moraceae family has about 800 species of woody trees, shrubs and vines [8]. These species are found mainly in tropical areas, and are used in medical practice worldwide $[8,9]$. The medicinal plants of genus Ficus contain triterpenes, polyphenols, flavonoids, sterols, alkaloids, coumarins and other secondary metabolites [10]. These phytochemicals are used as anti-rheumatic, antidiabetic, anti-helminthic, digestive, mildlaxative and anti-dysentery agents [11]. In the present study, six species of genus Ficus, namely, Ficus benghalensis, Ficus elasticaa, Ficus palmata, Ficus religiosa, Ficus semicordata and Ficus auriculata were screened for their anticoagulant potential.

\section{EXPERIMENTAL}

\section{Plant materials}

Leaves of $F$. benghalensis, $F$. elastica, $F$. palmata, $F$. religiosa, $F$. semicordata, and $F$. auriculata were collected from Azad Kashmir, Pakistan at coordinates $34.22^{\circ} \mathrm{N} 73.28^{\circ} \mathrm{E}$, in August 2016. The material was identified by Dr. Ajaib of the Department of Botany, Mirpur University of Science and Technology, Mirpur, Azad Jammu and Kashmir, Pakistan. The voucher specimens (no. MUST722 - MUST727) were deposited at the Herbarium of the Department of Biotechnology. The leaves were shade-dried at room temperature for 2 weeks, triturated with a blender and kept in sealed containers away from light and humidity until used.

\section{Extract preparation}

The dried leaf powder was soaked in methanol at a plant material: methanol ratio of 1:5 (w: $\mathrm{v})$ for 6 days. The soaked samples were occasionally shaken to ensure proper mixing. The mixture was then filtered using a muslin cloth and Whatman filter paper. The filtrate was further concentrated using a rotary evaporator, to obtain a semi-solid material i.e. crude methanol extract (MCE). A portion of the crude extract was dissolved in phosphate buffered saline (PBS) and used for biological screening.

\section{Fractionation of MCEs}

The MCEs were subjected to liquid-liquid partitioning using solvents of increasing polarity to obtain n-hexane, chloroform and ethyl acetate fractions. The fractions were dried through solvent evaporation in a rotary evaporator under reduced pressure.

\section{Phytochemical analysis}

\section{Determination of total phenolic content (TPC)}

The TPCs of the plant extracts were determined using the Folin-Ciocalteau method as reported by Harborne [12]. The principle involved in this assay is that polyphenols are reduced by FolinCiocalteau reagent to produce a blue-coloured complex, the intensity of which is proportional to the amount of polyphenol present. The concentrations of polyphenols in the plant extracts were calculated from a gallic acid standard calibration curve. For the calibration curve, different concentrations of gallic acid $(12.5,25,50,100,200$, and $400 \mu \mathrm{g} / \mathrm{mL})$ were prepared. Then, $0.5 \mathrm{~mL}$ of each solution was added to $2.5 \mathrm{~mL}$ of $10 \%$ Folin-Ciocalteau reagent and $2.5 \mathrm{~mL}$ of $7.5 \%$ sodium carbonate solution, followed by incubation at room temperature for $1 \mathrm{~h}$. Thereafter, the absorbance of the solution was read at $765 \mathrm{~nm}$ in a UVvisible spectrophotometer. The readings were 
taken in triplicate for each sample and the mean value was calculated. The same procedure was used for plant extracts. The TPC content was expressed as $\mathrm{mg}$ GAE/g of plant extract as shown in Equation 1:

$T P C=\frac{(C \times V)}{m}$

where $C$ is the concentration of gallic acid obtained from the calibration curve in $\mathrm{mg} / \mathrm{ml}$; $V$ is the volume of sample solution in $\mathrm{ml}$, and $m$ is the weight of plant extract.

\section{Determination of total flavonoid content}

The total flavonoid contents of the plant samples were measured using the method of Kumaran and Karunakaran [13]. In essence, $1 \mathrm{~mL}$ of extract solution was mixed with $1 \mathrm{~mL}$ of ethanolic solution of $\mathrm{AlCl}_{3}$ and $1.5 \mathrm{~mL}$ of $5 \%$ sodium acetate solution, followed by incubation at room temperature for $2.5 \mathrm{~h}$. The absorbance of the solution was measured at $440 \mathrm{~nm}$ in a UV-visible spectrophotometer. Triplicate measurements were made for each sample, and the mean of three values was taken. The same procedure was repeated for standard solution of rutin at different concentrations i.e. 12.5, 25, 50, 100, 200 , and $400 \mu \mathrm{g} / \mathrm{mL}$ to obtain a calibration curve. The total flavonoid content was expressed as mg rutin equivalent/g of sample, using the regression equation (Equation 2):

$Y=0.0067 x-0.1331, R^{2}=0.9781$

where $x$ is the absorbance and $y$ is the rutin equivalent.

\section{Determination of $\mathrm{LD}_{50}$ and rationalization of dose}

To determine the effective therapeutic dose, acute toxicity test of the crude methanol extract (MCE) was carried out on New Zealand rabbits. The rabbits were divided into four groups of four animals each ( $\mathrm{n}=4)$, and MCE was administered orally at doses of 1.0, 2.0, 3.0 and $4.0 \mathrm{~g} / \mathrm{kg}$ body weight to groups $1,2,3$ and 4 , respectively. The rabbits were kept under close observation for about $6 \mathrm{~h}$ after the MCE administration, and they remained under periodic observation for 5 days to monitor delayed toxicity, if any. The animals were monitored for changes in skin, fur, eyes, mucous membrane, CNS, respiration and circulation. Median lethal dose $\left(L D_{50}\right)$ greater than $2.0 \mathrm{~g} / \mathrm{kg}$ was considered safe, while one-tenth of the $L D_{50}$ was taken as the effective therapeutic dose.

\section{Evaluation of anticoagulant potential}

The anticoagulant potential of each plant sample was tested on human blood sample. For this purpose, six healthy human donors were selected. Care was taken to ensure that the blood donors had not taken any drugs for at least seven days prior to sampling period. The blood samples were collected in Eppendorf tubes containing $400 \mu \mathrm{L}$ of sodium citrate solution (3.2\%) in order to avoid blood clotting. Following centrifugation at $3000 \mathrm{rpm}$ at $5{ }^{\circ} \mathrm{C}$ for $15 \mathrm{~min}$, the resultant plasma samples were refrigerated at $4{ }^{\circ} \mathrm{C}$ prior to use.

\section{Prothrombin time (PT) assay}

The effect of plant extracts on the extrinsic pathway of coagulation was determined using the prothrombin time (PT) test as previously described by Felix-Silva et al [14], with slight modifications. The PT test was performed with commercially available $\mathrm{PT}$ reagent kit (Singapore Biosciences, Singapore). In essence, $90 \mu \mathrm{L}$ of plasma was mixed with 10 $\mu \mathrm{L}$ of plant extract at concentration of $1 \mu \mathrm{g} / \mu \mathrm{L}$, followed by incubation at $37^{\circ} \mathrm{C}$ for $5 \mathrm{~min}$. Then, $100 \mu \mathrm{L}$ of pre-warmed thromboplastin reagent (PT assay reagent) was added, and the clotting time was recorded with a digital timer. Plasma alone (with vehicle only) was used as normal control, while $0.5 \mathrm{U} / \mathrm{mL}$ of heparin was used as positive control.

\section{Activated partial thromboplastin time (APTT) assay}

The coagulation pathway is a cascade of events that lead to haemostasis. The intrinsic pathway consists of factors I, II, IX, X, XI, and XII otherwise known as fibrinogen, prothrombin, Christmas factor, Stuart-Prower factor, plasma thromboplastin, and Hageman factor, respectively. The common pathway consists of factors I, II, V, VIII, X which circulate in the bloodstream as zymogens and are activated by serine proteases, ultimately resulting in the activation of fibrinogen by conversion to fibrin. The effects of the plant extracts on the intrinsic pathway and common coagulation pathway were measured using the APTT assay according to a slight modification of the procedure outlined by Mao et al [15]. The test was similar to the PT test except that $100 \mu \mathrm{L}$ APTT assay reagent (cephaloplastin) was used. The reaction mixture was incubated at $37^{\circ} \mathrm{C}$ for $5 \mathrm{~min}$, followed by addition of $100 \mu \mathrm{L}$ of $25 \mathrm{mM}$ 
$\mathrm{CaCl}_{2}$. Then, the coagulation time was recorded.

\section{Statistical analysis}

The data collected were transferred to Graphpad prism 7 and plotted. Values are expressed as mean \pm standard error of the mean (SEM). Unpaired $t$-test was used for statistical analysis. Statistical significance was fixed at $p \leq 0.05$.

\section{RESULTS}

\section{Phytochemical profile}

\section{Total phenolic contents}

In this study, the six species of Ficus investigated were analysed for polyphenol contents using the Folin-Ciocalteu method. Although the FC method alone is not enough to determine the total phenolic content due to the diverse nature of polyphenols, it can give a considerably good estimation of the levels of these compounds. The results in Figure 1 show that the TPC content of the crude methanol extract of $F$. auriculata was $83.5 \pm 0.9 \mathrm{mg} \mathrm{GAE} / \mathrm{g}$. This was followed, in decreasing order of TPC content, by F. palmata $(49.5 \pm 0.3)$, and then $F$. religiosa $(47.0 \pm 0.4)$ $\mathrm{mgGAE} / \mathrm{g}$. Thus, total phenolic content was significantly higher $(p<0.05)$ in $F$. auriculata than in any other tested Ficus species.

The n-hexane fractions of $F$. benghalensis, $F$. elastica, $F$. palmata, $F$. semicordata, $F$. semicordata, and $F$. auriculata had TPC contents of $86 \pm 1.6,64 \pm 2.7,71 \pm 1.4,57.5 \pm 2.8,58.5 \pm$ 5 and $32.1 \pm 1 \mathrm{mg} \mathrm{GAE} / \mathrm{g}$, respectively; while the ethyl acetate fractions contained TPC levels of $86.5 \pm 1.5,41 \pm 5,26 \pm 0.05,31 \pm 3,85.5 \pm 1$ and $77.5 \pm 1.6 \mathrm{mg} \mathrm{GAE} / \mathrm{g}$, respectively. The TPC contents of the chloroform fractions of $F$. semicordata $(78.5 \pm 2.5 \mathrm{mg} \mathrm{GAE} / \mathrm{g})$ and $F$. religiosa (51 $\pm 1 \mathrm{mg} \mathrm{GAE} / \mathrm{g}$ ) were significantly higher than the corresponding level in the chloroform fraction of $F$. benghalensis (32.5 \pm 0.6 $m g G A E / g)$. Therefore, the results of the present study revealed that in the six Ficus species investigated, the amounts of TPC were higher in the n-hexane fractions than in the ethyl acetate and chloroform fractions. The chloroform fractions contained the least amounts of TPC.

\section{Total flavonoid contents}

The results of total flavonoid contents are shown in Figure 2. All the six species of Ficus investigated contained appreciable amounts of flavonoids ranging from $5.3 \pm 0.7$ to $11.8 \pm 0.3$ $\mathrm{mg} R E / \mathrm{g}$. The flavonoid contents of the crude methanol extract of $F$. elastica $(10 \pm 0.48$ $\mathrm{mgRE} / \mathrm{g})$ and $F$. auriculata $(7.35 \pm 0.44 \mathrm{mgRE} / \mathrm{g})$ were significantly higher than the corresponding values in the other species used in this study. The n-hexane fractions of $F$. benghalensis, $F$. elastica, $F$. palmata, $F$. semicordata, $F$. semicordata, and $F$. auriculata had flavonoid contents of $7.13 \pm 0.1,10.93 \pm 0.58,8.37 \pm 0.33$, $6.9 \pm 0.2,6.26 \pm 0.16$ and $7.05 \pm 0.32 \mathrm{mg} \mathrm{RE} / \mathrm{g}$, respectively.

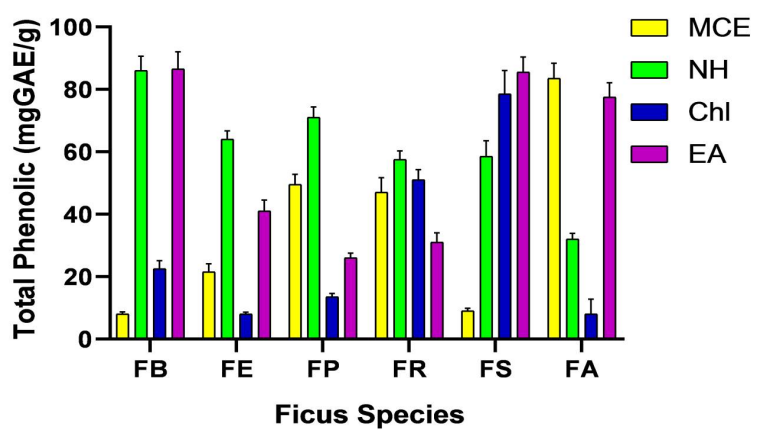

Figure 1: Total phenolic contents of the crude methanol extracts and other fractions of Ficus species expressed as $\mathrm{mgGAE} / \mathrm{g}$. A relatively high value of TPC was seen in each plant extract. All experiments were run in triplicate, and values are expressed as mean \pm SEM. FB: Ficus benghalensis; FE: Ficus elastica; FP: Ficus palmata; FR: Ficus religiosa; FS: Ficus semicordata; FA: Ficus auriculata; MCE: methanolic crude extract; $\mathrm{NH}$ : n-hexane; Chl: chloroform; EA: ethyl acetate

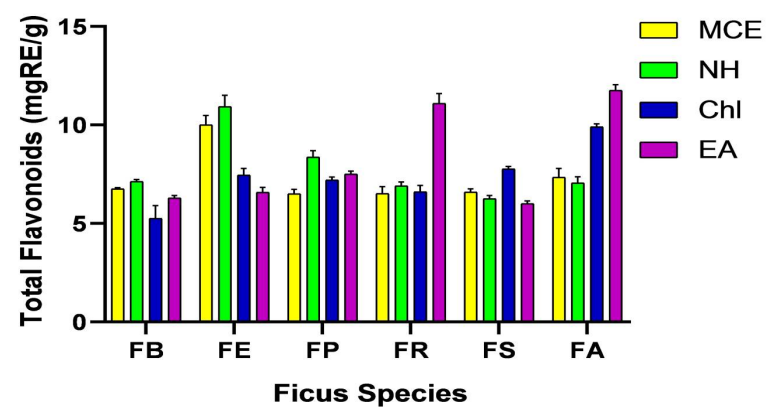

Figure 2: Total flavonoid contents of the crude methanol extracts and other fractions of six Ficus species expressed as $\mathrm{mg} \mathrm{RE} / \mathrm{g}$. Fairly good amounts of total flavonoids were obtained. The assays were run in triplicate, and values are expressed as mean \pm SEM. FB: Ficus benghalensis; FE: Ficus elastica; FP: Ficus palmata; FR: Ficus religiosa; FS: Ficus semicordata; FA: Ficus auriculata; MCE: crude methanol extract; $\mathrm{NH}$ : n-hexane; Chl: chloroform; EA: ethyl acetate

\section{Anticoagulant potential}

The effects of the crude methanol extracts of the six Ficus species and their fractions on haemostasis were evaluated using their anticoagulant potential through prothrombin time 
(PT) and the activated partial thromboplastin time (APTT) measurements. The PTs of crude methanol extracts of $F$. benghalensis, $F$. elastica, $F$. palmata, $F$. religiosa, $F$. semicordata, and $F$. auriculata were $21.7 \pm 1.2,18.3 \pm 0.9,17.3 \pm 1.1$, $20.3 \pm 1.4,22.7 \pm 1.7$ and $26.7 \pm 2.2 \mathrm{~s}$, respectively. The PT values of $n$-hexane ranged from $17.3 \pm 0.9$ to $21.0 \pm 1.0 \mathrm{~s}$. The corresponding ranges for chloroform and ethyl acetate were $17.7 \pm 0.7$ to $22.0 \pm 1.1$ and $17.8 \pm$ 0.9 to $24.0 \pm 1.5 \mathrm{~s}$, respectively. Therefore, the results showed that all fractions of the six Ficus species delayed prothrombin times, when compared to the negative control or normal control $(13.3 \pm 0.6 \mathrm{~s})$, as shown in Figure 3 . The n-hexane fraction of $F$. palmata had the lowest PT of $17.3 \pm 0.9 \mathrm{~s}$, while the ethyl acetate fraction of $F$. auriculata had the highest PT of $24.0 \pm 1.5 \mathrm{~s}$.

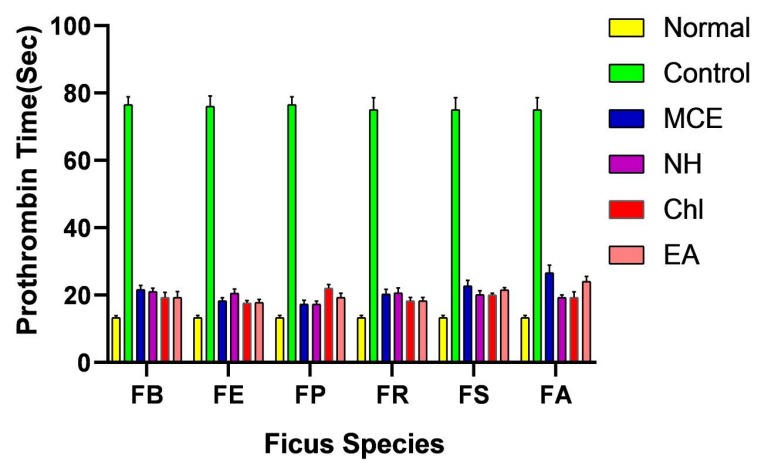

Figure 3: Prothrombin times of the crude methanol extracts and fractions of the six Ficus species. A relatively delayed $\mathrm{PT}$ was observed with each plant sample, relative to the normal group. The experiments were repeated three times, and values are expressed as mean \pm SEM. FB: Ficus benghalensis; FE: Ficus elastica; FP: Ficus palmata; FR: Ficus religiosa; FS: Ficus semicordata; FA: Ficus auriculata; MCE: methanolic crude extract; $\mathrm{NH}$ : $\mathrm{n}$-hexane; Chl: chloroform; EA: ethyl acetate

\section{Activated partial thromboplastin time}

The activated partial thromboplastin times of the crude methanol extracts of the six Ficus species and their $n$-hexane, chloroform and ethyl acetate fractions were determined using APTT assay reagent. The results (Figure 4) showed delayed APTT, when compared to normal. The activated partial thromboplastin time of crude methanol extracts of $F$. benghalensis, $F$. elastica, $F$. palmata, $F$. religiosa, $F$. semicordata, and $F$. auriculata were $67.3 \pm 3.2,58.7 \pm 4.5,65.7 \pm 5.0$, $71.0 \pm 3.3,64.3 \pm 4.7$ and $70.3 \pm 5.5 \mathrm{sec}$, respectively (Figure 4). The APTT values for $n$ hexane, chloroform and ethyl acetate fractions ranged from $51.7 \pm 2.4$ to $72.3 \pm 5.4,49.7 \pm 6.1$ to $71.7 \pm 5.5$, and $47.7 \pm 3.3$ to $69.7 \pm 2.9 \mathrm{~s}$, respectively. Thus, the fractions of all six Ficus species showed significantly higher APTT than normal $(43.3 \pm 3.1 \mathrm{~s})$. The ethyl acetate fraction of $F$. religiosa had the lowest APTT of $47.7 \pm 3.3$ $\mathrm{s}$, while $\mathrm{n}$-hexane fraction of $F$. religiosa produced the highest APTT of $72.3 \pm 5.4 \mathrm{~s}$.

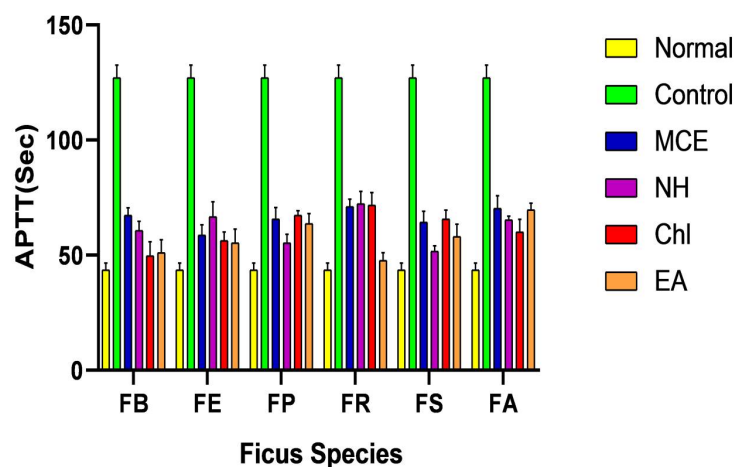

Figure 4: Activated partial thromboplastin times of the crude methanol extracts of the six Ficus species and their solvent fractions. A relatively delayed APPT was observed in each test sample, when compared to the normal group. The experiments were carried out in triplicate, and values are expressed as mean \pm SEM. FB: Ficus benghalensis; FE: Ficus elastica; FP: Ficus palmata; FR: Ficus religiosa; FS: Ficus semicordata; FA: Ficus auriculata; MCE: methanolic crude extract; $\mathrm{NH}$ : n-hexane; Chl: chloroform; EA: ethyl acetate

\section{DISCUSSION}

The results of the current study showed that all the six Ficus species investigated had anticoagulant potential. Moreover, the fractions obtained from the leaf extracts of these Ficus species contained variable concentrations of phenolic and flavonoid compounds. Polyphenols constitute the largest group of phytochemicals, with more than 8000 different phenolic compounds of which more than 4000 are flavonoids [16]. Due to their diverse chemical nature, polyphenols exhibit antimicrobial, antioxidant, anti-allergic, anti-inflammatory, antiaging, and anticancer properties [17]. Thus, they are gaining popularity in the pharmaceutical, food and cosmetic industries [18]. The results of the present study revealed that the Ficus species investigated contained significant amounts of phenolic compounds. The crude methanol extract of $F$. auriculata had the highest total phenolic content amongst the six Ficus species.

Flavonoids have great potential in medical care due to their broad-ranging anti-inflammatory, anticancer, antibacterial and antioxidant activities. Moreover, flavonoid-rich foods are extensively employed in traditional medicines for treating different diseases [18]. The results obtained in this study showed that the six species of Ficus investigated contained appreciable amounts of flavonoids ranging from 
$5.25 \pm 0.65$ to $11.8 \pm 0.29 \mathrm{mg} \mathrm{RE} / \mathrm{g}$. The flavonoids were significantly higher in the crude methanol extracts of $F$. elastica and $F$. auriculata than in any of the other Ficus species studied.

The crude methanol extracts and their n-hexane, chloroform and ethyl acetate fractions showed anticoagulant properties, as seen in delayed prothrombin times ranging from $17.3 \pm 0.9$ to $26.7 \pm 2.2$ sec. Similarly, the crude extracts and their n-hexane, chloroform and ethyl acetate fractions produced delayed APTT, when compared to control. This is the first study to report the anticoagulant potential of six species of genus Ficus. These results are strongly supported by the presence of significant amounts of phenolic and flavonoid compounds. Moreover, previous studies have reported strong antioxidant potential of other species of the genus Ficus [1921].

\section{CONCLUSION}

The therapeutic potentials of medicinal plants have made alternative medicine research one of the most promising fields of biomedical research. The findings of the current study indicate the good anticoagulant potentials of crude methanol extracts of leaves of six Ficus species and their fractions, with $F$. semicordata and $F$. religiosa demonstrating higher anticoagulant activity than the other Ficus species.

\section{DECLARATIONS}

\section{Conflict of interest}

No conflict of interest is associated with this work.

\section{Contribution of authors}

We declare that this work was done by the authors named in this manuscript, and that all liabilities pertaining to claims relating to the content of this manuscript will be borne by the authors. Sumaira Ambreen contributed to the design of the study and participated in carrying out the experiments. Muhammad Tariq conceived the idea, participated in the design of the study, analysed the data, and prepared the manuscript. Muhammad S, Masoud took part in designing of the study and drafting of the final manuscript. Imran Ali contributed to data analysis and helped in drafting the manuscript. Muhammad Qasim participated in the analysis of data and drafting of the manuscript. Aamar Mushtaq conducted the sampling and the extraction of plant material and helped in in vitro studies as well. Maqsood Ahmed helped in preparing the manuscript. Rehana Asghar provided the facility and proofread the manuscript. All authors read and approved the final manuscript for publication.

\section{Open Access}

This is an Open Access article that uses a funding model which does not charge readers or their institutions for access and distributed under the terms of the Creative Commons Attribution License (http://creativecommons.org/licenses/by/ 4.0) and the Budapest Open Access Initiative (http://www.budapestopenaccessinitiative.org/rea d), which permit unrestricted use, distribution, and reproduction in any medium, provided the original work is properly credited.

\section{REFERENCES}

1. Lee W, Lee S, Choi J, Park JH, Kim KM, Jee JG, Bae JS. Antithrombotic properties of JJ1, a potent and novel thrombin inhibitor. Sci Rep 2017; 7(1): 14862. doi: 10.1038/s41598-017-13868-1.

2. Lee W, Lee J, Kulkarni R, Kim MA, Hwang JS, Na M, Bae JS; Antithrombotic and antiplatelet activities of smallmolecule alkaloids from Scolopendra subspinipes mutilans. Sci Rep 2016; 6: 21956. doi: 10.1038/srep21956.

3. Liu L, Duan JA, Tang Y, Guo J, Yang N, Ma $H$, Shi $X$. Taoren-Honghua herb pair and its main components promoting blood circulation through influencing on hemorheology, plasma coagulation and platelet aggregation. Journal of Ethnopharmacology 2012; 139(2): 381-387.doi: 10.1016/j.jep.2011.11.016.

4. Xie $P$, Cui L, Shan $Y$, Kang WY. Antithrombotic effect and mechanism of radix paeoniae rubra. Biomed Res Int 2017; 2017: 9475074. doi: 10.1155/2017/9475074.

5. Sahoo N, Choudhury K, Manchikanti P. Manufacturing of biodrugs need for harmonization in regulatory standards. BioDrugs 2009; 23(4): 217-229. doi: 10.2165/11317110-000000000-00000.

6. Dangarembizi $R$, Erlwanger KH, Moyo D, Chivandi E. Phytochemistry, pharmacology and ethnomedicinal uses of Ficus thonningii (Blume Moraceae). a review. Afr $J$ Tradit Complement Altern Med 2013; 10(2): 203-212.

7. Olusola A, Lajide L, Ajayi OO, Amoo IA. Morphological and physicochemical characterization of ipin gum (Ficus elasticaa). Sch. Acad. J. Biosci.2014; 2(11): 773-777

8. Serrato A, Ibarra-Manríquez G, Oyama K. Biogeography and conservation of the genus Ficus (Moraceae) in Mexico. Journal of Biogeography 2004; 31(3): 475-485.

9. Hansson A, Zelada JC, Noriega HP. Reevaluation of risks with the use of Ficus insipida latex as a traditional anthelmintic remedy in the Amazon. J Ethnopharmacol 2005; 98(3): 251-257. doi: 10.1016/j.jep.2004.12.029. 
10. Ramadan MA, Ahmad AS, Nafady AM, Mansour Al. Chemical composition of the stem bark and leaves of Ficus pandurata Hance. Nat Prod Res 2009; 23(13): 1218-1230. doi: 10.1080/14786410902757899

11. Trivedi $C P$, Shinde $S$ and Sharma RC. Preliminary phytochemical and pharmacological studies on Ficus racemosa (Gular). Indian J Med Res 1969; 57(6): 10701074.

12. Harborne JB, Williams CA. Advances in flavonoid research since 1992. Phytochemistry 2000; 55(6): 481 504.

13. Kumaran $A$, Joel $R$ Karunakaran. In vitro antioxidant activities of methanol extracts of five Phyllanthus species from India. LWT - Food Science and Technology 2007; 40(2): 344-352. doi: 10.1016/j.Iwt.2005.09.011.

14. Félix-Silva J, Souza $T$, Camara RB, Cabral B, SilvaJúnior $A A$, Rebecchi IM, Zucolotto $S M$, Rocha $H A$, Fernandes-Pedrosa $M$. In vitro anticoagulant and antioxidant activities of Jatropha gossypiifolia $L$. (Euphorbiaceae) leaves aiming therapeutical applications. BMC Complementary and Alternative Medicine 2014; 14: 405. doi:10.1186/1472-6882-14-405

15. Mao W, Li H, Li Y, Zhang H, Qi X, Sun H, Chen Y, Guo S. Chemical characteristic and anticoagulant activity of the sulfated polysaccharide isolated from Monostroma latissimum (Chlorophyta). Int J Biol Macromol 2009; 44(1): 70-74. doi: 10.1016/j.ijbiomac.2008.10.003.
16. Tsao R. Chemistry and biochemistry of dietary polyphenols. Nutrients 2010; 2(12): 1231. doi: 10.3390/nu2121231.

17. Ayoub M, Camargo AC, Shahidi F. Antioxidants and bioactivities of free, esterified and insoluble-bound phenolics from berry seed meals. Food Chem 2016; 197(Pt A): 221-232. doi: 10.1016/j.foodchem.2015.10.107.

18. Awad NE, Seida AA, Hamed MA, Mahmoud AH, Elbatanony MM. Phytochemical and in vitro screening of some Ficus and Morus spp. for hypolipidaemic and antioxidant activities and in vivo assessment of Ficus mysorensis (Roth). Nat Prod Res 2012; 26(12): $1101-$ 1011. doi: 10.1080/14786419.2010.545353.

19. Eshwarappa RS, lyer S, Subaramaihha SR, Richard SA, Dhananjaya BL. Antioxidant activities of Ficus glomerata (moraceae) leaf gall extracts. Pharmacognosy Res 2015; 7(1): 114-120. doi: 10.4103/0974-8490.147225

20. Shivasharanappa K, Londonkar R. Evaluation of total phenolic content and free radical scavenging activity of Ficus glomerata Roxb. International Journal of Pharmaceutical and Clinical Research, 2014; 6(2): 133137.

21. Jain A, Ojha V, Kumar G, Karthik L, Rao KVB. Phytochemical composition and antioxidant activity of methanolic extract of Ficus benjamina (Moraceae) leaves. Research J. Pharm. and Tech. 2013; 6(11): 1184-1189. 